\title{
A REPERCUSSÃO DA QUEBRA DA CADEIA DE CUSTÓDIA DA PROVA NO PROCESSO PENAL
}

RVD

Recebido em

09.10 .2020

Aprovado em.

25.11 .2020 CUSTODY ON CRIMINAL PROCEDURE

\author{
Renata Ribeiro Espírito Santo 1 \\ Igor de Andrade Barbosa ${ }^{2}$ \\ Osnilson Rodrigues Silva ${ }^{3}$
}

\section{RESUMO}

$\mathrm{O}$ presente artigo descreve $\mathrm{o}$ instituto implementado no ordenamento jurídico com a aprovação da Lei Anticrime, a chamada cadeia de custódia da prova penal. O objetivo do mesmo é apresentar a repercussão da quebra da cadeia de custódia dentro do processo penal. Para tanto, foram realizados levantamentos doutrinários nos sentidos favoráveis e contrários. Após a análise desses posicionamentos, constatou-se que é preciso cautela antes de optar pela exclusão da prova decorrente da quebra do instituto mencionado anteriormente, uma vez que o Brasil é um país com enorme desigualdade social, e, portanto, os estados não gozam dos mesmos recursos financeiros para a execução deste como um todo.

PALAVRAS-CHAVE: Cadeia; Custódia; Lei; Anticrime; Quebra.

\section{ABSTRACT}

The following article describes the institute implemented in the Brazilian legal system with the approval of Anti-Crime Law, the so-called chain of custody. Its purpose is to

\footnotetext{
1 Discente do curso de Direito do Centro Universitário Católica do Tocantins - UniCatólica. E-mail: renata.santo@a.catolica-to.edu.br. ORCID: https://orcid.org/0000-0003-4717-7084

2 Mestre em Direito Econômico e Desenvolvimento pelo Programa de Mestrado em Direito da Universidade Candido Mendes - UCAM. Especialista em Relações de Consumo e em Direito da Concorrência e Propriedade Industrial, ambos pela UCAM. Defensor Público Federal de $1^{\circ}$ categoria na Defensoria Pública da União do Tocantins e professor de graduação e pós-graduação do curso de Direito do Centro Universitário Católica do Tocantins - UniCatólica. E-mail: igor.barbosa@catolica-to.edu.br. ORCID: https://orcid.org/0000-0001-6337-3873

${ }^{3}$ Graduado em Filosofia pela UNESP-Marília, especialista em Filosofia pela UCB e Mestre em Prestação Jurisdicional e Direitos Humanos pela UFT. Atua como professor no Ensino Superior e Médio. Email: osnilson@catolica-to.edu.br. ORCID: https://orcid.org/0000-0001-9972-9106
} 
present the repercussions of the break on the chain of custody within the criminal procedure. To this end, doctrinal surveys were carried out in both favorable and opposite ways. After analyzing these positions, it was found that caution is needed before opting for the exclusion of the evidence resulting from the broke of the aforementioned institute, since Brazil is a country with enormous social inequality, and, therefore, the states do not enjoy the financial resources for the execution of this as a whole.

KEYWORDS: Anti-Crime; Law; Chain; Custody; Break.

\section{INTRODUÇÃO}

A Lei $n^{0}$ 13.964/2019, mais conhecida como "Pacote Anticrime", promoveu expressivas alterações no âmbito normativo da justiça criminal, com influência direta na alçada dos papiloscopistas policiais. Em meio a tantas mudanças, algumas têm relação, objetiva ou subjetiva, no sistema de investigação preliminar processual penal, como é o caso da cadeia de custódia da prova.

Em uma cena criminal, dentre as muitas funções de um agente policial, tem-se como principal a procura por vestígios que possuam algum valor probatório no crime em investigação. Não há que discutir que o exame detalhado da cena do crime é um passo crucial de todo o processo forense.

Entende-se como vestígio todos os objetos, marcas, corpos ou matéria que possam ter relação com o fato investigado e o acusado para o delineamento até a definição da autoria e elucidação do crime.

Após a análise pericial, caso os vestígios demonstrem-se diretamente relacionados com o delito investigado, estes transformam-se em evidências ou indícios, e posteriormente em provas. Para que estas evidências sejam permitidas como provas no processo, os vestígios devem ser colhidos com base nos princípios e procedimentos estabelecidos pelo Código de Processo Penal, para assim formar uma cadeia de custódia da prova.

A cadeia de custódia da prova penal é definida no dispositivo em questão como o conjunto de todos os procedimentos utilizados para manter e documentar a história cronológica do vestígio coletado em locais ou em vítimas de crimes, para rastrear sua 
posse e manuseio a partir de seu reconhecimento até o descarte. A prova, por sua vez, é o fio condutor entre o fato sob exame e a convicção do julgador.

Assim, a implantação da cadeia de custódia, com a aprovação do Pacote Anticrime, representou um grande avanço no ordenamento jurídico brasileiro. Dessa forma, fica nítido que o instituto supracitado trará maior segurança jurídica ao processo penal, ao mesmo tempo que acarretará desafios aos agentes atuantes.

\section{O ADVENTO DA LEI ANTICRIME}

Há muito tempo, clama-se por uma abrangente reforma do sistema criminal legislativo brasileiro, o que inclui o Código Penal, o Código de Processo Penal, a Lei de Execução Penal e as mais variadas Leis Especiais. Enquanto inexistir esta possibilidade, é mais conveniente proporcionar modificações pontuais do que continuar na mesmice.

O Governo, ao assumir o Brasil a partir do início do ano de 2019, comprometeuse a criar um pacote anticrime, com a garantia de que este endureceria o tratamento da lei para com os criminosos, enfatizando aqueles pertencentes a organizações criminosas.

Para dar início a esta parte teórica da pesquisa, tem-se que, de acordo com a ementa da Lei Federal no 13.964, de 24 de dezembro de 2019, bem como seu artigo 1ㅜ, a Lei Anticrime é um conjunto de normas penais que aperfeiçoa a legislação penal e processual penal. Como apontam as pesquisas de Marina Pacheco Batista e Mylena de Aguiar Melo:

O pacote é composto por dois projetos de lei e um projeto de lei complementar que alteram 14 leis como o Código Penal (Decreto-lei 2.848/40), o Código de Processo Penal (CPP, Decreto-lei 3.689/41), a Lei de Execução Penal (7.210/84), a Lei de Crimes Hediondos (8.072/90), o Código Eleitoral (4.737/65), com a finalidade de combate à corrupção. (BATISTA; MELO, 2019).

Conforme Junqueira, Vanzolini, Fuller e Pardal: 
O foco do projeto foi o recrudescimento do tratamento à criminalidade violenta, por um lado, e, em contrapartida, um tratamento mais rápido e brando aos crimes leves e não violentos, evitando o processo e o encarceramento, com a criação de acordo de não persecução penal, desafogando as Varas Criminais e evitando a pena de prisão nesses casos. (JUNQUEIRA; VANZOLINI; FULLER; PARDAL, 2020, p. 7)

Segundo Nucci (2020, p. 1) "a legislação tornou-se mais rigorosa em certos pontos, exatamente onde havia necessidade, mas poderia ter seguido adiante, prevendo institutos modernos e eliminando certas situações antiquadas e sem sucesso". Pode-se citar como exemplo os regimes fechado, semiaberto e aberto.

Contudo, vale ressaltar os desafios dos órgãos atuadores:

Se, por um lado, se assiste à intensificação de uma tendência políticocriminal de cunho negocial, que entrega grande protagonismo e responsabilidade às atividades persecutórias desde seu nascedouro, por outro, parte substancial dessas alterações representa desafios ao Ministério Público brasileiro, figurando como uma previsível consequência desse movimento reformador. (MPPR, 2020).

Apesar das numerosas críticas de especialistas, antagonistas políticos e movimentos sociais durante todo o processo de aprovação do projeto de lei, o Pacote Anticrime acarretou uma série de alterações positivas e revolucionárias no ordenamento jurídico brasileiro.

\section{A IMPORTÂNCIA DA PROVA NO PROCESSO PENAL}

A prova é o conjunto de ações praticadas pelas partes, pelo juiz e por terceiros, com o objetivo de formular a convicção do magistrado a respeito da falsidade ou veracidade de um acontecimento ou de uma alegação.

Nas palavras de Pacelli:

A prova judiciária tem um objetivo claramente definido: a reconstrução dos fatos investigados no processo, buscando a maior coincidência 
possível com a realidade histórica, isto é, com a verdade dos fatos, tal como efetivamente ocorridos no espaço e no tempo. A tarefa, portanto, é das mais difíceis, quando não impossível: a reconstrução da verdade (PACELLI, 2017, p. 174).

Concerne, por conseguinte, a todo e qualquer âmbito de compreensão praticado pelo ser humano com o propósito de comprovar a verdade de uma afirmação.

Nesse sentido, adverte Capez:

Sem dúvida alguma, o tema referente à prova é o mais importante de toda a ciência processual, já que as provas constituem os olhos do processo, o alicerce sobre o qual se ergue toda a dialética processual. Sem provas idôneas e válidas, de nada adianta desenvolverem-se aprofundados debates doutrinários e variadas vertentes jurisprudenciais sobre temas jurídicos, pois a discussão não terá objeto. (CAPEZ, 2020, p. 383)

Sob a ótica de Nereu José Giacomolli (2008, p. 09) prova são os meios utilizados para demonstração dos fatos; atividade utilizada pelas partes para levar ao processo os meios de prova, designando, também o resultado do procedimento probatório.

Conforme o artigo científico de Matos:

Por mais que os avanços tecnológicos e científicos venham contribuindo com as ciências forenses para melhorar a capacidade de reunir evidências utilizadas na solução em processos criminais ou civis (Access Excellence The National Health Museum, 2006), estes avanços, por si só, não representam garantia que estas evidências serão aceitas como prova pericial pela justiça. (MATOS, 2016, p.1)

Diante desse pano de fundo, destaca Geraldo Prado (2019):

Mais uma vez coube à dinâmica dos casos penais o relevante papel de levantar o véu que encobria com o manto do indiscutível a séria questão da prova dos fatos. No lugar da verdade real o tribunal enfrentou o tema dos standards de constituição e configuração da prova penal, inconfundíveis com o standard de prova do direito anglo-americano 
tomado em sua vertente de medida de prova que, mais especificamente para o processo penal, é o standard da prova além da dúvida razoável.

Como pontuou Alan Dershowitz, renomado advogado e professor na Harvard Law School, "os científicos buscam a verdade. Os filósofos buscam a moral. Um processo penal busca somente a prova mais além de toda a dúvida razoável".

Com isso, vale destacar a fala da ministra Rosa Weber, no julgamento de uma ação penal originária:

A presunção de inocência, princípio cardeal no processo criminal, é tanto uma regra de prova como um escudo contra a punição prematura. Como regra de prova, a formulação mais precisa é o standard anglosaxônico no sentido de que a responsabilidade criminal deve ser provada acima de qualquer dúvida razoável (proof beyond a reasonable doubt). (AP 580/SP, Dje de 26/6/2017).

Nesse cenário, Prado menciona que:

Assim, se o juízo de partida de toda investigação penal é a incerteza, afirmada pela presunção de inocência, e a punição apenas estará legitimada quando superado este estado de incerteza, o tipo de «processo» adequado constitucionalmente é aquele que se caracteriza por viabilizar o conhecimento da infração penal e sua autoria em um esquema lógico e jurídico que esteja apto a apoiar a decisão em um determinado contexto de «verdade». (PRADO, 2014).

Por todo exposto, tem-se que no processo penal a exigência do standard de prova é muito mais alto que no processo civil, pois exige-se que a culpabilidade do réu esteja demonstrada "mais além de toda a dúvida razoável. 4

Nesse contexto, a perícia é um tipo de prova admitido no processo penal que resume-se em um exame elaborado por um profissional técnico-científico, quanto a acontecidos imprescindíveis ao desfecho da causa.

No conceito de Didier Júnior, Braga e Oliveira:

${ }^{4}$ NIEVA FENOLL, 2010. 
A prova pericial é aquela pela qual a elucidação do fato se dá com o auxílio de um perito, especialista em determinado campo do saber, devidamente nomeado pelo juiz, que deve registrar sua opinião técnica e científica no chamado laudo pericial - que poderá ser objeto de discussão pelas partes e seus assistentes técnicos. (DIDIER JÚNIOR. BRAGA. OLIVEIRA. 2012, p. 227)

Desse modo, a prova pericial é posta na legislação brasileira como um meio de prova lícita, à qual outorga-se certo valor especial, uma vez que sua posição está ocupada entre a prova e a sentença. Representa um plus em relação à prova e um minus em relação à sentença. (CAPEZ, 2020, p. 430)

O artigo 158, do Código de Processo Penal, prevê que "quando a infração deixar vestígios, será indispensável o exame de corpo de delito, direto ou indireto, não podendo supri-lo a confissão do acusado". Conforme apontam as pesquisas do artigo científico de Adrualdo Lima Catão, Meline Lopes e Rafael Moreira da Silva (2014, p. 117):

O tema é abordado por diversos autores, após acurada análise de vários títulos doutrinários, que a prova pericial, como se faz perceber pelo próprio nome, é a possibilidade da juridicização do resultado do trabalho técnico de um profissional de determinada área, que, não possuindo o juiz qualificação apropriada para emitir pareceres específicos que fogem ao seu conhecimento jurídico, determina que um perito o faça por meio de laudo.

É de extrema magnitude para a segurança jurídica do sistema legislativo, que sejam permitidas apenas provas periciais que encontrem respaldo na Constituição Federal, e vedadas as provas ilícitas ou ilegítimas no julgamento do processo.

\section{A CADEIA DE CUSTÓDIA DA PROVA PENAL}

Nesse contexto, foi criada a cadeia de custódia da prova penal para a garantia do Estado de Direito. Este, no que Ihe toca, remete-se à submissão ao império do Direito, com observância ao respeito das normas e direitos fundamentais. 
No conceito de Prado (2014), "o estado de direito tem nas regras do devido processo legal sua base jurídico-política, por meio da qual o exercício legítimo do monopólio da força tende a não se converter em arbítrio."

Já os juristas políticos Danilo Zolo e Pietro Costa destacam que "colocado no seu horizonte histórico-genético, o estado de direito evoca, portanto, o problema da relação entre os sujeitos, o direito e o poder".

De acordo com Dias Filho (2012, p.401), "o termo "cadeia" designa uma sucessão de fenômenos que criam as condições de possibilidade para 0 desenvolvimento do seu subsequente; a "custódia" indica o ato ou efeito de preservar, proteger algo ou alguém". Segundo Carlos Edinger, a cadeia de custódia é:

[...] composta de elos, que dizem respeito a um vestígio que, por sua vez, eventualmente, será considerado uma prova. Um elo é qualquer pessoa que tenha manejado esse vestígio. É dever do Estado e, também, direito do acusado, identificar, de maneira coerente e concreta, cada elo, a partir do momento no qual o vestígio foi encontrado. Assim, fala-se em cadeia de custódia íntegra quando se fala em uma sucessão de elos provados. "[Cada um deles] proporciona a viabilidade do desenvolvimento do seguinte [elo], de forma a proteger a integridade de um vestígio do local do crime ao seu reconhecimento com prova material, até o trânsito em julgado." (EDINGER, 2016, p. 237-257)

A Lei no 13.964/2019 apresentou ao Código de Processo Penal os conceitos de cadeia de custódia e vestígio.

Ademais, determinou quando dá-se o início, além de reconhecer o agente público como o responsável por sua preservação:

Art. 158 - A Considera-se cadeia de custódia o conjunto de todos os procedimentos utilizados para manter e documentar a história cronológica do vestígio coletado em locais ou em vítimas de crimes, para rastrear a sua posse e manuseio a partir de seu reconhecimento até o descarte.

§1ํㅡ início da cadeia de custódia dá-se com a preservação do local de crime ou com procedimentos policiais ou periciais nos quais seja detectada a existência de vestígio. 
https://doi.org/10.20873/uft.2359-0106.2021.v8n1.p392-409

$\S 2^{\circ} \mathrm{O}$ agente público que reconhecer um elemento como de potencial interesse para a produção da prova pericial fica responsável por sua preservação.

§3o Vestígio é todo objeto ou material bruto, visível ou latente, constatado ou recolhido, que se relaciona à infração penal.

Sob essa ótica, o legislador buscou ser didático e elucidativo. Este, por sua vez, definiu não só o conceito de cadeia de custódia, como também todos os estágios:

Art. 158-B. A cadeia de custódia compreende o rastreamento do vestígio nas seguintes etapas:

I - reconhecimento: ato de distinguir um elemento como de potencial interesse para a produção da prova pericial;

II - isolamento: ato de evitar que se altere o estado das coisas, devendo isolar e preservar o ambiente imediato, mediato e relacionado aos vestígios e local de crime;

III - fixação: descrição detalhada do vestígio conforme se encontra no local de crime ou no corpo de delito, e a sua posição na área de exames, podendo ser ilustrada por fotografias, filmagens ou croqui, sendo indispensável a sua descrição no laudo pericial produzido pelo perito responsável pelo atendimento;

IV - coleta: ato de recolher o vestígio que será submetido à análise pericial, respeitando suas características e natureza;

$\mathrm{V}$ - acondicionamento: procedimento por meio do qual cada vestígio coletado é embalado de forma individualizada, de acordo com suas características físicas, químicas e biológicas, para posterior análise, com anotação da data, hora e nome de quem realizou a coleta e o acondicionamento;

VI - transporte: ato de transferir o vestígio de um local para o outro, utilizando as condições adequadas (embalagens, veículos, temperatura, entre outras), de modo a garantir a manutenção de suas características originais, bem como o controle de sua posse;

VII - recebimento: ato formal de transferência da posse do vestígio, que deve ser documentado com, no mínimo, informações referentes ao número de procedimento e unidade de polícia judiciária relacionada, local de origem, nome de quem transportou o vestígio, código de rastreamento, natureza do exame, tipo do vestígio, protocolo, assinatura e identificação de quem o recebeu;

VIII - processamento: exame pericial em si, manipulação do vestígio de acordo com a metodologia adequada às suas características biológicas, físicas e químicas, a fim de se obter o resultado desejado, que deverá ser formalizado em laudo produzido por perito;

IX - armazenamento: procedimento referente à guarda, em condições adequadas, do material a ser processado, guardado para realização de contraperícia, descartado ou transportado, com vinculação ao número do laudo correspondente; 
X - descarte: procedimento referente à liberação do vestígio, respeitando a legislação vigente e, quando pertinente, mediante autorização judicial.

Nesse cenário, o novo dispositivo legal estabeleceu a preferência por perito oficial para a realização da coleta dos vestígios, e, também, o encaminhamento para a central de custódia quando assim for necessário:

Art. 158-C. A coleta dos vestígios deverá ser realizada preferencialmente por perito oficial, que dará o encaminhamento necessário para a central de custódia, mesmo quando for necessária a realização de exames complementares.

$\S 1^{\circ}$ Todos vestígios coletados no decurso do inquérito ou processo devem ser tratados como descrito nesta Lei, ficando órgão central de perícia oficial de natureza criminal responsável por detalhar a forma do seu cumprimento.

$\S 2^{\circ}$ É proibida a entrada em locais isolados bem como a remoção de quaisquer vestígios de locais de crime antes da liberação por parte do perito responsável, sendo tipificada como fraude processual a sua realização.

Nesse âmbito, o Código de Processo Penal salientou os recipientes permitidos e a suas respectivas formas de uso:

Art. 158-D. O recipiente para acondicionamento do vestígio será determinado pela natureza do material.

$\S 1^{\circ}$ Todos os recipientes deverão ser selados com lacres, com numeração individualizada, de forma a garantir a inviolabilidade e a idoneidade do vestígio durante o transporte.

$\S 2^{\circ}$ O recipiente deverá individualizar o vestígio, preservar suas características, impedir contaminação e vazamento, ter grau de resistência adequado e espaço para registro de informações sobre seu conteúdo.

§3ํำ recipiente só poderá ser aberto pelo perito que vai proceder à análise e, motivadamente, por pessoa autorizada.

\$4ำ Após cada rompimento de lacre, deve se fazer constar na ficha de acompanhamento de vestígio o nome e a matrícula do responsável, a data, o local, a finalidade, bem como as informações referentes ao novo lacre utilizado.

§5 O lacre rompido deverá ser acondicionado no interior do novo recipiente. 
Não obstante, a Lei Anticrime instaurou a obrigatoriedade da existência da central de custódia em todos os Institutos de Criminalística, assim como a indispensabilidade da gestão ser vinculada diretamente ao órgão central de perícia oficial de natureza criminal:

Art. 158-E. Todos os Institutos de Criminalística deverão ter uma central de custódia destinada à guarda e controle dos vestígios, e sua gestão deve ser vinculada diretamente ao órgão central de perícia oficial de natureza criminal.

$\$ 1^{\circ}$ Toda central de custódia deve possuir os serviços de protocolo, com local para conferência, recepção, devolução de materiais e documentos, possibilitando a seleção, a classificação e a distribuição de materiais, devendo ser um espaço seguro e apresentar condições ambientais que não interfiram nas características do vestígio.

§ $\mathrm{Na}$ central de custódia, a entrada e a saída de vestígio deverão ser protocoladas, consignando-se informações sobre a ocorrência no inquérito que a eles se relacionam.

$\S$ 3ำ Todas as pessoas que tiverem acesso ao vestígio armazenado deverão ser identificadas e deverão ser registradas a data e a hora do acesso.

§ 4ํㅜ Por ocasião da tramitação do vestígio armazenado, todas as ações deverão ser registradas, consignando-se a identificação do responsável pela tramitação, a destinação, a data e horário da ação.

Art. 158-F. Após a realização da perícia, o material deverá ser devolvido à central de custódia, devendo nela permanecer. Parágrafo único. Caso a central de custódia não possua espaço ou condições de armazenar determinado material, deverá a autoridade policial ou judiciária determinar as condições de depósito do referido material em local diverso, mediante requerimento do diretor do órgão central de perícia oficial de natureza criminal. (BRASIL, 2020).

Diante desse pano de fundo, o artigo científico de Jefferson Lemes Carvalho destaca que:

[...] A CC [cadeia de custódia] nas instituições periciais oficiais nacionais é o meio que se pode garantir a confiança, autenticidade e integridade das amostras (vestígios), desde o isolamento do local da infração penal e coleta - perícia externa; encaminhamento, armazenamento, análise e devolução por parte dos laboratórios periciais - perícia interna. (CARVALHO, 2016) 
Diz respeito, portanto, a um dispositivo dirigido a assegurar a fiabilidade do elemento probatório, ao colocá-lo sob proteção de interferências capazes de falsificar o resultado da atividade probatória (PRADO, 2014, p.86). A cadeia de custódia tem sido reconhecida como o elo fraco em investigações criminais. $O$ valor da evidência pode ser perdido se os procedimentos não forem adequadamente constituídos (MACHADO, 2017, p. 10).

A quebra ou perda da cadeia de custódia (break on the chain of custody) deve ser resolvida no plano da inadmissibilidade, que impede a valoração da prova e implica a sua exclusão no processo. (DIAS FILHO, 2012, p. 401)

Geraldo Prado leciona que:

[...] a tradição do controle da ilicitude probatória tem o mérito de incorporar um efeito dissuassório - deterrent efect - que serve de desestímulo às agências repressivas quanto à tentação de recorrerem a práticas ilegais para obter a punição. (PRADO, 2014, p. 92)

Junqueira, Vanzolini, Fuller e Pardal complementam que:

[...] a apreciação da questão não pode ser diferida ou postergada para a fase de valoração da prova, pois a quebra da cadeia de custódia impede a sujeição do material probatório remanescente aos procedimentos de comprovação e refutação (insuficiência probatória), subtraindo ao acusado as possibilidades de defesa, contrariedade e conhecimento da integralidade das fontes de prova (paridade de armas e devido processo legal). (JUNQUEIRA; VANZOLINI; FULLER; PARDAL, 2020, p. 198).

Nessa perspectiva, o STJ decidiu pela exclusão da prova decorrente de quebra da cadeia de custódia:

RECURSO ESPECIAL. ART. 305 DO CPM. NULIDADE. INTERCEPTAÇÃO TELEFÔNICA. PROVA EMPRESTADA. QUEBRA DA CADEIA DE CUSTÓDIA DA PROVA. FALTA DE ACESSO À INTEGRALIDADE DAS CONVERSAS. EVIDENCIADO PELO TRIBUNAL DE ORIGEM A EXISTÊNCIA DE ÁUDIOS DESCONTINUADOS, SEM ORDENACCÃO, SEQUENCIAL LÓGICA E COM OMISSÃO DE TRECHOS DA DEGRAVAÇÃO. FILTRAGEM ESTABELECIDA SEM A PRESENÇA DO DEFENSOR. NULIDADE 
RECONHECIDA. PRESCRIÇÃO CONFIGURADA. RECURSOS PROVIDOS. DECRETADA A EXTINÇÃO DA PUNIBILIDADE. 1. A quebra da cadeia de custódia tem como objetivo garantir a todos os acusados o devido processo legal e os recursos a ele inerentes, como a ampla defesa, o contraditório e principalmente o direito à prova lícita. $O$ instituto abrange todo o caminho que deve ser percorrido pela prova até sua análise pelo magistrado, sendo certo que qualquer interferência durante o trâmite processual pode resultar na sua imprestabilidade ( $\mathrm{RHC}$ 77.836/PA, Rel. Ministro RIBEIRO DANTAS, QUINTA TURMA, julgado em 05/02/2019, DJe 12/02/2019). 2. É dever o Estado a disponibilização da integralidade das conversas advindas nos autos de forma emprestada, sendo inadmissível a seleção pelas autoridades de persecução de partes dos áudios interceptados. 3. A apresentação de parcela do produto extraído dos áudios, cuja filtragem foi estabelecida sem a presença do defensor, acarreta ofensa ao princípio da paridade de armas e ao direito à prova, porquanto a pertinência do acervo probatório não pode ser realizado apenas pela acusação, na medida em que gera vantagem desarrazoada em detrimento da defesa. 4. Reconhecida a nulidade, inegável a superveniência da prescrição, com fundamento no art. 61 do CPP. 5. Recursos especiais providos para declarar a nulidade da interceptação telefônica e das provas dela decorrentes, reconhecendo, por consequência, a superveniência da prescrição da pretensão punitiva do Estado, de ofício. (STJ - REsp: 1795341 RS 2018/0251111-5, Relator: Ministro NEFI CORDEIRO, Data de Julgamento: 07/05/2019, T6 - SEXTA TURMA, Data de Publicação: DJe 14/05/2019)

Entretanto, contrapõe Nucci:

É preciso frisar que o Brasil é um país continental, de modo que, se a cadeia de custódia pode ser bem executada num Estado mais rico, como o Paraná, pode enfrentar muitas dificuldades, até pelas imensas distâncias, em Estados como o Amazonas. Portanto, o simples descumprimento da cadeia de custódia não deve gerar nulidade absoluta. (NUCCl, 2020, p. 71).

Na mesma linha, Eugênio Pacelli sustenta que:

De outro lado, conquanto possa ser justificado sob fundamentação diversa, porque não se pode esperar outra atitude de um Estado que se proclama democrático e de Direito, é possível, também, atribuir à ampla defesa o direito ao aproveitamento, pelo réu, até mesmo de provas obtidas ilicitamente, cuja introdução no processo, em regra, é inadmissível. $E$ isso porque, além da exigência da defesa efetiva, o 
princípio desdobra-se, dada a sua amplitude, para abarcar todas e quaisquer modalidades de prova situadas no ordenamento jurídico, até mesmo aquelas vedadas à acusação, pois não se pode 3.3.1.5 perder de vista que a ampla defesa é cláusula de garantia individual instituída precisamente no interesse do acusado (art. 5으. CF). De mais a mais, tratando-se de prova destinada à demonstração da inocência, poder-seá alegar até mesmo a exclusão de sua ilicitude, impondo-se uma leitura mais ampla do estado de necessidade, para o fim de não se exigir a ciência do agente acerca da necessidade do comportamento e/ou de sua eminência. Pode-se afirmar, portanto, que a ampla defesa realiza-se por meio da defesa técnica, da autodefesa, da defesa efetiva e, finalmente, por qualquer meio de prova hábil a demonstrar a inocência do acusado. (PACCELI, 2017, p. 38 e 39).

Em observâncias aos direitos fundamentais, é importante salientar o artigo 5응 da Constituição da República Federativa do Brasil: "Todos são iguais perante a lei sem distinção de qualquer natureza, garantindo-se aos brasileiros e aos estrangeiros residentes no país a inviolabilidade do direito à vida, à segurança e à propriedade (...)".

Nessa linha, a expressão aristotélica: "Devemos tratar igualmente os iguais e os desigualmente os desiguais, na medida de sua desigualdade" evidencia o princípio da igualdade presente no dispositivo supracitado no parágrafo anterior.

Diante desse pano de fundo, é permitido tratamento desigual em situações de desigualdade fática, como a admissibilidade de provas em casos os quais foram inviáveis a perfeita execução da cadeia de custódia da prova penal por motivos de força maior.

Para reforçar essa ideia, Tourinho Filho reconhece que:

$\mathrm{Na}$ verdade, se a inadmissibilidade das provas ilícitas está no capítulo destinado aos direitos e garantias fundamentais do homem, não pode repugnar à comum consciência jurídica o fato de a defesa conseguir por meio ilícito prova que demonstre a inocência do imputado. Poder-se-á, então, dizer: male captum, bene retentum. [...] É preciso que nos pratos afilados da balança sejam pesados os bens jurídicos envolvidos, e, à evidência, a tutela do direito de liberdade do indivíduo "es un valor más importante para la sociedad" que a tutela do outro bem protegido pela proteção do sigilo. Assim, uma interceptação telefônica, mesmo ao arrepio da lei, se for necessariamente essencial a demonstrar a inocência do acusado, não pode ser expungida dos autos. Entre o sigilo 
das comunicações e o direito de liberdade, este supera aquele. (TOURINHO FILHO, 1999, p. 234).

Em conformidade, Vicente Greco Filho leciona que:

[...] nenhuma regra constitucional é absoluta, uma vez que tem de conviver com outras regras ou princípios também constitucionais. Assim, continuará a ser necessário o confronto ou peso entre os bens jurídicos, desde que constitucionalmente garantidos, a fim de se admitir, ou não, a prova obtida por meio ilícito. Veja-se, por exemplo, a hipótese de uma prova decisiva para a absolvição obtida por meio de uma ilicitude de menor monta. Prevalece o princípio da liberdade da pessoa, logo a prova será produzida e apreciada, afastando-se a incidência do inc. LVI do art. $5^{\circ}$ da Constituição, que vale como princípio, mas não absoluto, como se disse. (GRECO FILHO, 1998, p. 200).

Desse modo, Susan Haack (2013, p.74) aponta ainda que "en todo sistema jurídico es necesario determinar, de alguna forma, cuestiones de hecho; sin embargo, los distintos sistemas jurídicos tienen (o han tenido) diferentes maneras de hacerlo".

Twinning reitera que:

Las reglas que gobiernan los procedimientos penales 'tienen por objeto proporcionar una decisión justa de cada proceso criminal' y están 'construidas para asegurar la simplicidad en el procedimiento, la imparcialidad en la administración, y la eliminación de gastos y retrasos injustificados" (TWINNING, 2015, p. 121).

Nesse sentido, Geraldo Prado (2014, p. 14) conclui que:

A oposição ideológica entre as dimensões e métodos probatórios, portanto, não deve ser ocultada. Ela integra a feição epistemológica de qualquer método de aferição ou arbitramento de responsabilidade penal. Dizer, no entanto, que se adota uma concepção racional-legal de justiça e do processo, com o processo judicial orientado à investigação da verdade possível, na medida em que "uma reconstrução verídica dos fatos da causa é uma condição necessária da justiça e da legalidade da decisão", não implica de modo obrigatório assumir o partido de uma exclusiva dimensão probatória - a epistêmica - em detrimento dos modelos hermenêutico, retórico-persuasivo ou contextual. (PRADO, 2014, p. 14). 
Assim, é possível notar tanto os pontos positivos como também os negativos da aplicação do instituto supramencionado no contexto brasileiro, posto que a não aplicação à risca deste pode acarretar em prejuízos irreparáveis para os sujeitos do processo penal, sob pena de ameaça aos direitos fundamentais.

\section{CONSIDERAÇÕES FINAIS}

Inicialmente, o desenvolvimento da presente pesquisa foi uma tarefa um tanto complexa, principalmente em função da escassez de materiais atualizados acerca do tema. Cuidou a pesquisadora no sentido de realizar o levantamento bibliográfico e uma revisão de literatura para, assim, compor a tese, antítese e síntese.

Nesse sentido, a relevância da temática da cadeia de custódia das provas deve-se à sua repercussão nos processos penais, e consequentemente, a exigência de maior regulamentação do direito fundamental à liberdade, a qual clama pela positivação de regras rígidas propícias à padronização de todo o procedimento de custódia.

Diante do exposto, fica claro que a doutrina majoritária defende a admissibilidade da prova no processo decorrente da quebra da cadeia de custódia, desde que essa seja a única forma de inocentar alguém. Por outro lado, a corrente minoritária e a Suprema Corte entendem pela exclusão da mesma do processo.

Logo, deve-se observar com muita cautela a exclusão da prova no processo decorrente da quebra da cadeia de custódia, haja vista que o Brasil é um país desigual socialmente e, portanto, os estados possuem discrepância significativa para a execução da cadeia de custódia como um todo.

\section{REFERÊNCIAS}

ANDERSON, Terence; SCHUM, David; TWINING, William. Análisis de la prueba. Madrid: Marcial Pons, 2015. 
BRASIL. Lei no 13.964, de 24 de dezembro de 2019. Lei Anticrime. Diário Oficial da União, 24 de dezembro de 2019. Disponível em: http://www.planalto.gov.br/ccivil 03/ ato2019-2022/2019/lei/L13964.htm. Acesso em: 11 abr. 2020.

Ministério Público do Estado do Paraná. Lei Anticrime: Apontamentos Iniciais sobre a Lei no 13.964/2019. Curitiba, 2020. Disponível em: https://criminal.mppr.mp.br/arquivos/File/Estudo - Lei Anticrime Apontamentos CAOPCrim-MPPR.pdf. Acesso em: 15 set. 2020.

.Decreto lei no 3.689, de 03 de outubro de 1941. Código de Processo Penal. Disponível em: http://www.planalto.gov.br/CCIVIL/Decreto-Lei/Del3689.htm. Acesso em: 20 maio 2020.

.Constituição (1988). Constituição da República Federativa do Brasil. Brasília, DF: Senado Federal: Centro Gráfico, 1988.

Superior Tribunal de Justiça - REsp: 1795341 RS 2018/0251111-5, Relator: Ministro NEFI CORDEIRO, Data de Julgamento: 07/05/2019, T6 - SEXTA TURMA, Data de Publicação: DJe 14/05/2019. Disponível em: https://sti.jusbrasil.com.br/jurisprudencia/709372796/recurso-especial-resp-1795341-rs2018-0251111-5/relatorio-e-voto-709372848. Acesso em: 15 set. 2020.

CAPEZ, Fernando. Curso de processo penal. 27. ed. São Paulo: Saraiva, 2020.

CARVALHO, Jefferson Lemes. Cadeia de custódia e sua relevância na persecução penal. Brazilian Journal of Forensic Sciences, Medical Law and Bioethics. 2016. Disponível em: http://www.ipebj.com.br/forensicjournal/download.php?arquivo=220. Acesso em: 20 maio 2020.

CATÃO, Adrualdo de Lima. LOPES, Meline. DA SILVA, Rafael Moreira. O caráter completante da prova pericial na resolução de lides em processo civil. Cadernos de Graduação - Ciências humanas e sociais. 2014. v-2. n-1. p. 117-134. Disponível em: https://periodicos.set.edu.br/fitshumanas/article/view/1345/795. Acesso em: 12 set. 2020.

COSTA, Pietro. ZOLO, Danilo. Estado de direito: história, teoria e crítica. São Paulo: Martins Fontes, 2006, p. XI.

DIAS FILHO, Claudemir Rodrigues. Cadeia de custódia: do local do crime ao trânsito em julgado; do vestígio à evidência. São Paulo: Revista dos Tribunais, 2012, p. 401. Disponível em: https://dspace.almg.gov.br/handle/11037/28039. Acesso em: 15 set. 2020. 
EDINGER, Carlos. Cadeia de custódia, rastreabilidade probatória. Revista Brasileira de Ciências Criminais, vol.120, maio/jun. 2016, p. 237-257. Disponível em: https://www.academia.edu9/Cadeia de Cust\%C3\%B3dia Rastreabilidade Probat\%C3 \%B3ria. Acesso em: 15 set. 2020.

GIACOMOLLI, Nereu José. Reformas do processo penal - considerações críticas. Rio de Janeiro: Editora Lumen Juris, 2008.

HAACK, Susan. El probabilismo jurídico: una disensión epistemológica. In: Vázquez, Carmen (ed.). Estándares de prueba y prueba científica: Ensayos de epistemología jurídica. Madrid: Marcial Pons, Ediciones Jurídicas y sociales, S.A., 2013. p. 66.

GRECO FILHO, Vicente. Manual de processo penal. 5. ed. São Paulo: Saraiva, 1998.

JUNQUEIRA, Gustavo. VANZOLINI, Patricia. FULLER, Paulo Henrique. PARDAL, Rodrigo. Lei anticrime comentada - artigo por artigo. Saraiva: São Paulo, 2020.

MACHADO, Michelle Moreira. Importância da cadeia de custódia para prova pericial. Revista Criminalística e Medicina Legal, 2017. V-1, n. 2, P. 8-12. Disponível em: http://revistacml.com.br/wp-content/uploads/2018/04/RCML-2-01.pdf. Acesso em: 11 abr. 2020.

MATOS, Emirene. Cadeia de custódia na investigação criminal nos limites do processo penal. Revista Científica do ISCTAC, [S.I.], v. 3, n. 9, jan. 2017. ISSN 2519-7207. Disponível em: http://www.isctac.ac.mz/revista/index.php/revistacientifica/article/view/79. Acesso em: 13 jun. 2020.

MENDES, Soraia da Rosa. MARTíNEZ, Ana Maria. Pacote anticrime: comentários críticos à Lei 13.964/2019. 1. ed. São Paulo: Atlas, 2020.

NUCCI, Guilherme. Pacote anticrime comentado. 1. ed. São Paulo: Forense, 2020.

PACELLI, Eugênio. Curso de processo penal. 21. ed. rev., atual. e ampl. - São Paulo: Atlas, 2017.

PRADO, Geraldo. Prova penal e sistema de controles epistêmicos: a quebra da cadeia de custódia das provas obtidas por métodos ocultos. São Paulo: Marcial Pons, 2014.

TOURINHO FILHO, Fernando da Costa. Processo penal. 21. ed. São Paulo: Saraiva, 1999. 